\title{
Second-Order Sliding Mode Control for Variable Speed Wind Turbine Experiment System
}

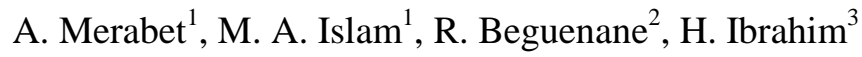 \\ ${ }^{1}$ Division of Engineering \\ Saint Mary's University \\ 923 Robie Street, Halifax, NS, B3H 3C3 Canada \\ Phone number: +001902 420 5712, email: adel.merabet@smu.ca \\ ${ }^{2}$ Royal Military College \\ Kingston, ON, K7K 7B4 Canada \\ ${ }^{3}$ Wind Energy Techno-Centre \\ Gaspe, QC, G4X 1G2 Canada
}

\begin{abstract}
In this work, a second-order sliding mode control algorithm is proposed for variable speed laboratory size DC generator wind turbine experiment system in order to track a speed profile and operate the wind turbine at maximum power extraction. The turbine torque, which varies with the wind speed, is considered as an unknown disturbance and rejected by the sliding mode strategy. The sliding mode controller has been integrated into a multivariable control system to operate the experimental wind turbine. Experimental results show that the proposed control system can achieve favourable speed tracking performance and robust with regard to parameter variations and external turbine disturbance.
\end{abstract}

\section{Key words}

Sliding mode, speed tracking, MPPT, wind turbine, DC generator.

\section{Introduction}

Sliding mode control provides a satisfactory performance with a simple control structure. It is insensitive to model imprecision caused from unmodeled dynamics, unknown disturbances and variation in parameters. The sliding mode control input is a combination of the equivalent control, which is carried out from the model of the physical system, and the commutation control, which plays the role of attracting the state trajectory to the switching surface during the convergence mode. This control technique is characterized by a discontinuous control action with an ideal infinite frequency. However, chattering phenomenon occurs due to implementation issues of the sliding mode control signal in digital devices operating with a finite sampling frequency, where the switching frequency of the control signal cannot be fully implemented. A solution to this problem is a high order sliding mode technique. This control technique maintains the same sliding mode properties with the advantage of eliminating the chattering problem due to the continuous-time nature of the control action [1-4].

In this paper, speed controller, based on second-order sliding mode, is proposed for a laboratory size DC generator wind turbine system for operation at maximum power extraction. The rotational speed and load voltage are controlled through a power electronics interface of buck-boost DC converters configuration. This interface can be used to operate the wind turbine at variable speed and regulate the load voltage to be constant [5]. The overall control system consists of the proposed speed controller and a current controller, with maximum power point tracking (MPPT) controller, acting as machine side converter control system and a voltage control, to maintain fixed load voltage, acting as load side converter control system.

\section{Wind Turbine}

The mechanical dynamic of the rotor driven at a speed $\omega$ by the turbine torque $T_{t}$ is expressed as

$$
\frac{d \omega(t)}{d t}=\frac{1}{J}\left(T_{t}-T_{e m}\right)-\frac{B}{J} \omega(t)+\frac{1}{J} \zeta
$$

where, $T_{e m}$ is the electromagnetic torque developed by the generator, $J$ is the rotor inertia, $B$ is the viscous-friction coefficient, and $\zeta$ represent the unmodeled quantities and external disturbance.

The developed electromagnetic torque $T_{e m}$ is given by

$$
T_{e m}(t)=K_{i} i(t)
$$


where, $K_{i}$ is the torque constant and $i$ is the generator current.

The torque produced by the wind at the shaft of the generator-turbine is given by the following expression

$$
T_{t}(t)=0.5 \pi \rho C_{t} r^{3} v_{w}^{2}
$$

where, $\rho$ is the air density, $C_{t}$ is the torque coefficient, $r$ is the radius of the turbine blade, $v_{w}$ is the wind speed.

\section{Second Order Sliding Mode Speed Control}

From equations (1) and (2), the dynamic equation of the rotational speed is rearranged as

$$
\dot{\omega}(t)=-A_{p} \omega(t)-B_{p} i(t)+d(t)
$$

where, $A_{p}=\frac{B}{J}, B_{p}=\frac{K_{i}}{J}$, and $d(t)=\frac{1}{J}\left(\zeta+T_{t}\right)$

$d(t)$ is an unknown bounded perturbation term, which may include parameters' variation, unmodeled quantities and external disturbances. Furthermore, it includes the turbine torque considered as an unknown disturbance due to the lack of information about the characteristics of the wind turbine and the non-measurement of wind speed.

The controller is developed to reach zero speed tracking error

$$
e_{\omega}(t)=\omega(t)-\omega_{\text {ref }}(t)
$$

where, $\omega_{\text {ref }}$ is the speed reference.

The time derivative of the speed tracking error is given by

$$
\begin{aligned}
\dot{e}_{\omega}(t) & =\dot{\omega}(t)-\dot{\omega}_{\text {ref }}(t) \\
& =u(t)+\left(-A_{p} e_{\omega}(t)+d(t)\right)
\end{aligned}
$$

where, $u(t)$ is the new command input and defined as

$$
u(t)=-B_{p} i(t)-A_{p} \omega_{\text {ref }}(t)-\dot{\omega}_{\text {ref }}(t)
$$

Suppose that the perturbation term $\left(-A_{p} e_{\omega}(t)+d(t)\right)$ of the system (6) is globally bounded by

$$
\left|d(t)-A_{p} e_{\omega}(t)\right| \leq \delta\left|e_{\omega}\right|^{1 / 2}
$$

for some constant $\delta \geq 0$.

The super-twisting sliding mode controller for perturbation and chattering elimination [6-7] is given by

$$
\begin{aligned}
& u=-k_{1}\left|e_{\omega}\right|^{1 / 2} \operatorname{sign}\left(e_{\omega}\right)+v \\
& \dot{v}=-k_{2} \operatorname{sign}\left(e_{\omega}\right)
\end{aligned}
$$

where, $k_{1}$ and $k_{2}$ are positive constant.
The closed loop system (6) and (9) results in

$$
\begin{aligned}
& \dot{e}(t)=-k_{1}\left|e_{\omega}\right|^{1 / 2} \operatorname{sign}\left(e_{\omega}\right)+v-A_{p} e_{\omega}(t)+d(t) \\
& \dot{v}=-k_{2} \operatorname{sign}\left(e_{\omega}\right)
\end{aligned}
$$

In order to study the stability of the closed loop system under the control law (9), let's define the following Lyapunov function candidate

$$
\begin{aligned}
V_{1} & =2 k_{2}\left|e_{\omega}\right|+\frac{1}{2} v^{2}+\frac{1}{2}\left(k_{1}\left|e_{\omega}\right|^{1 / 2} \operatorname{sign}\left(e_{\omega}\right)-v\right)^{2} \\
& =\xi^{T} P \xi
\end{aligned}
$$

where,

$$
\xi^{T}=\left[\left|e_{\omega}\right|^{1 / 2} \operatorname{sign}\left(e_{\omega}\right) \quad v\right], P=\left[\begin{array}{cc}
4 k_{2}+k_{1}^{2} & -k_{1} \\
-k_{1} & 2
\end{array}\right]
$$

Its time derivative along the solution of (6) results as follows

$$
\dot{V}_{1}=-\frac{1}{\left|e_{\omega}\right|^{1 / 2}} \xi^{T} Q \xi+\frac{d-A_{p} e_{\omega}}{\left|e_{\omega}\right|^{1 / 2}} q^{T} \xi
$$

where,

$$
Q=\frac{1}{2}\left[\begin{array}{cc}
2 k_{2}+k_{1}^{2} & -k_{1} \\
-k_{1} & 1
\end{array}\right], q^{T}=\left[\left(2 k_{2}+\frac{k_{1}^{2}}{2}\right)-\frac{k_{1}}{2}\right]
$$

Applying the bounds on the perturbation (8), as demonstrated in [6], it can be shown that

$$
\dot{V}_{1} \leq-\frac{1}{\left|e_{\omega}\right|^{1 / 2}} \xi^{T} \tilde{Q} \xi
$$

where,

$$
\tilde{Q}=\left[\begin{array}{cc}
2 k_{2}+k_{1}^{2}-\left(\frac{4 k_{2}}{k_{1}}+k_{1}\right. \\
-\left(k_{1}+2 \delta\right) & -\left(k_{1}+2 \delta\right)
\end{array}\right]
$$

$\dot{V}_{1}$ is negative if $\tilde{Q} \geq 0$, which is valid if the gains satisfy

$$
\begin{aligned}
& k_{1}>2 \delta \\
& k_{2}>k_{1} \frac{5 k_{1} \delta+4 \delta^{2}}{2\left(k_{1}-2 \delta\right)}
\end{aligned}
$$

Therefore, the origin $e_{\omega}=0$ is an equilibrium point that is strongly globally asymptotically stable [6].

Finally, from (7) and (9), the current command $i^{*}$ is

$$
\begin{aligned}
& i^{*}(t)=\frac{1}{B_{p}}\left[-A_{p} \omega_{\text {ref }}(t)-\dot{\omega}_{\text {ref }}(t)+k_{1}\left|e_{\omega}\right|^{1 / 2} \operatorname{sign}\left(e_{\omega}\right)-v\right] \\
& \dot{v}=-k_{2} \operatorname{sign}\left(e_{\omega}\right)
\end{aligned}
$$

The advantage of this controller is that the information about the turbine torque, therefore the wind speed, is not required and its effect will be rejected to enhance the speed tracking performance. 


\section{Multivariable Control for the Wind Turbine Experimental System}

The control system of a wind energy conversion system is multivariable as several quantities need to be regulated in order to operate the system efficiently. In the laboratory wind turbine experiment system, used in this work, a current controller is carried out to act in cascade with the speed sliding mode controller, MPPT system is performed to provide the speed reference to be tracked and, in order to maintain a proper functioning of load, voltage controller is integrated. The objective is to verify the behavior of the sliding mode controller in a multivariable control system.

\section{A. Current Controller}

The output of the speed controller (15) is a current set point applied to the current controller, which is developed from the electrical equation of DC generator given by

$$
\frac{d i(t)}{d t}=-\frac{R}{L} i(t)+\frac{K_{b}}{L} \omega(t)-\frac{1}{L} V(t)
$$

where, $R$ is the resistance, $L$ is the inductance, $i$ is the current, $\omega$ is the rotor speed, and $K_{b}$ is back-emf constant.

In this work, a Proportional-Integral (PI) based current controller has been implemented to track the current reference provided by the second-order sliding mode speed controller such as

$$
V^{*}=K_{P} e_{i}(t)+K_{I} \int e_{i}(t) d t
$$

where, $e_{i}(t)=i(t)-i^{*}(t)$ is the current error.

\section{B. Maximum Power Point Tracking Controller}

The efficient operation of any wind turbine is based on the extraction of the maximum power available from wind. Therefore, the turbine should operate at optimum tip speed ratio, to maximize the power coefficient, by controlling its rotational speed to track the optimum speed of rotation $[8$, 9]. In case of non-availability of wind turbine characteristics and wind speed measurements, a controller is needed to track the maximum power point by providing a speed reference to be followed by the turbine rotor.

In this work, MPPT control algorithm [10], based on the power change, has been implemented to find the speed reference as shown in Fig. 1. The power is calculated from the measurements of voltage and currents across the generator. In order to improve the speed tracking at variable wind speeds, the value of the parameter $k_{3}$ should change with the variation of the turbine speed. The following expression has been used to update that parameter.

$$
k_{3}=\alpha \cdot \omega(t)
$$

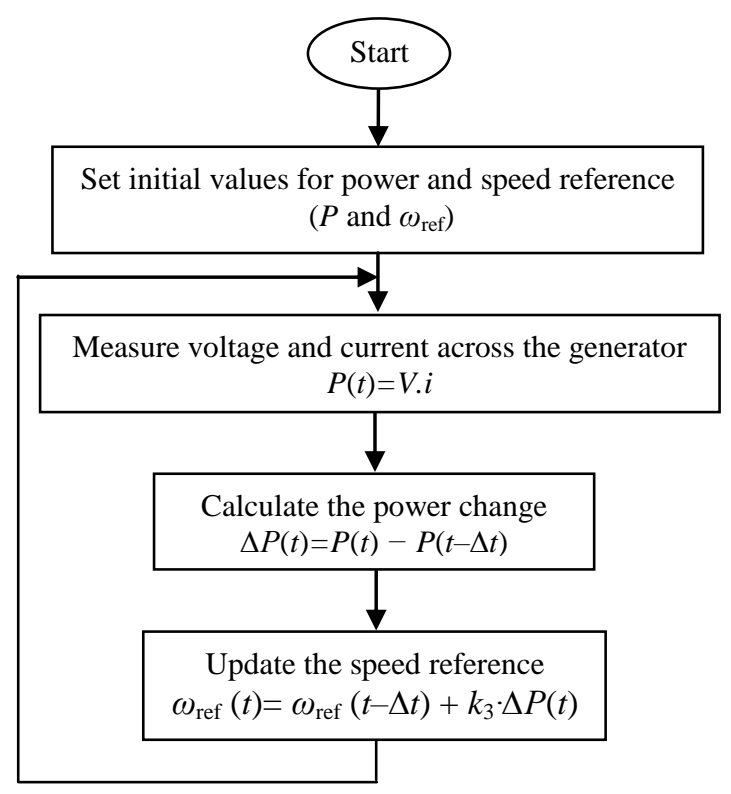

Fig. 1. MPPT controller

\section{Load Side Converter Control}

The load side converter control system is used to regulate the voltage $V_{L}$ across the load in order to maintain a proper functioning of the LED based load. The voltage controller is based on a PI regulator with gains $k_{p}$ and $k_{i}$

$$
U^{*}=k_{p}\left(V_{L}-V_{L}^{*}\right)+k_{i} \int\left(V_{L}-V_{L}^{*}\right) d t
$$

Its output is the firing signal to be delivered to the gate of the MOSFET in the DC-DC buck converter.

The bloc diagram of the sliding mode control, MPPT and the load side control of the experimental wind turbine is shown in Fig. 2.

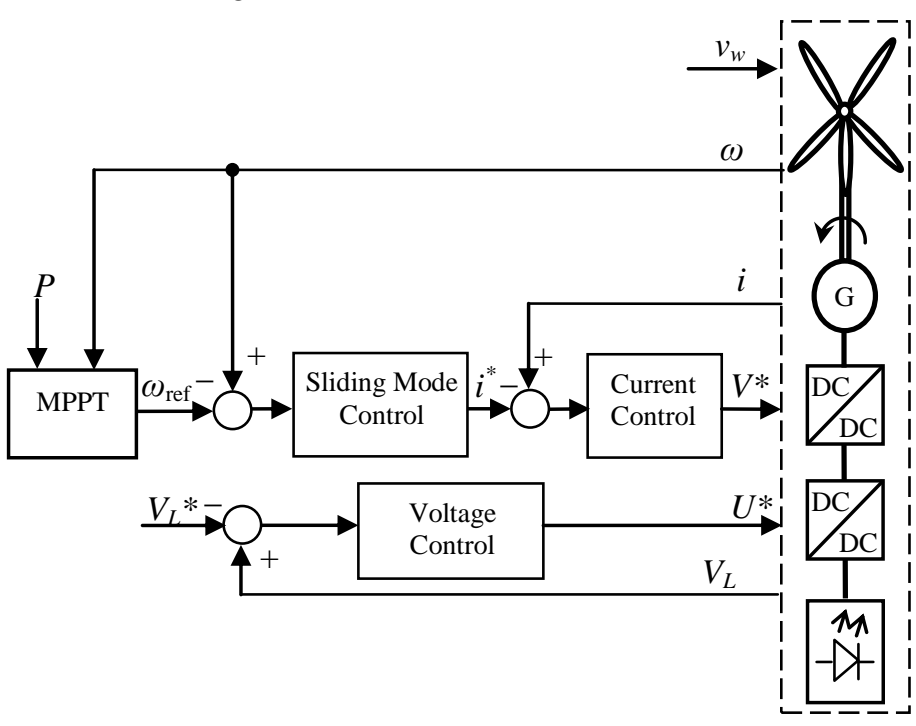

Fig. 2. Second-order sliding mode and multivariable controller for the DC generator wind turbine experimental system

where, $\alpha$ is a positive gain 


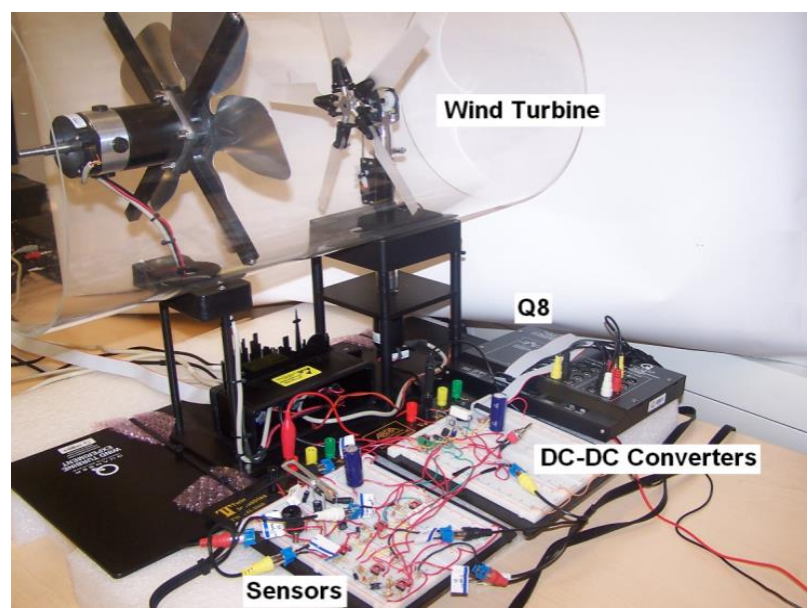

Fig. 3. DC generator wind turbine experimental system

\section{Experimental Results}

The wind turbine experimental system, manufactured by Quanser Inc. [11], consists of five blades wind turbine connected with a DC generator, as shown in Fig. 2, through a power electronics interface of two controlled DC-DC converters. The DC-DC buck converter is used to regulate the rotational speed of the generator shaft and the DC-DC boost converter is used to regulate the load voltage [5]. Voltage and current sensors are available in the system to measure the voltage/current in the generator's armature and the voltage across the load. The measurements are sent to the computer (PC), via the real-time data acquisition board Q8-USB, to be analysed using the software package QUARC with MATLAB/Simulink. QUARC is a powerful rapid control prototyping tool that significantly accelerates control system design and implementation [12].

The wind speed is artificially generated by a DC blower motor. An incremental encoder mounted on the blower rotor shaft is used to measure its speed, which will be considered equivalent to the wind speed as this information is not available. The wind speed profile is shown in Fig. 4. The advantage of the proposed control system is that it does not need information about the wind speed to evaluate the turbine torque, which will be rejected by the controller.

First, the experiment is carried out for a variable step speed reference to verify the controller performance at sudden change scenarios and in a multivariable control system. It can observed, from the results shown in Fig. 5, that the controller provide good tracking performance after a transient regime due to the initial wind speed from the blower. Furthermore, the behavior of the controller is still good at the sudden change in the speed reference.

Then, MPPT controller is integrated into the multivariable control system. From the results shown in Fig.6, the variation of the speed reference is similar to the one of the wind speed profile. Also, the turbine rotor tracks that speed reference with good performance as the tracking speed error is around zero after a transient regime, which guarantees maximum power extraction. The command input and the load voltage are given in Fig. 6 and 7 respectively. It can be observed that the load voltage is fluctuating around the constant voltage level due to the variation of the rotational speed and more studies need to be performed in order to keep a constant voltage.

Finally, in order to test the robustness of the controller, the system parameters in the control law (15) have been increased with $50 \%$ of their nominal values. A good performance of the speed tracking, as shown in Fig. 8, is still successfully achieved.

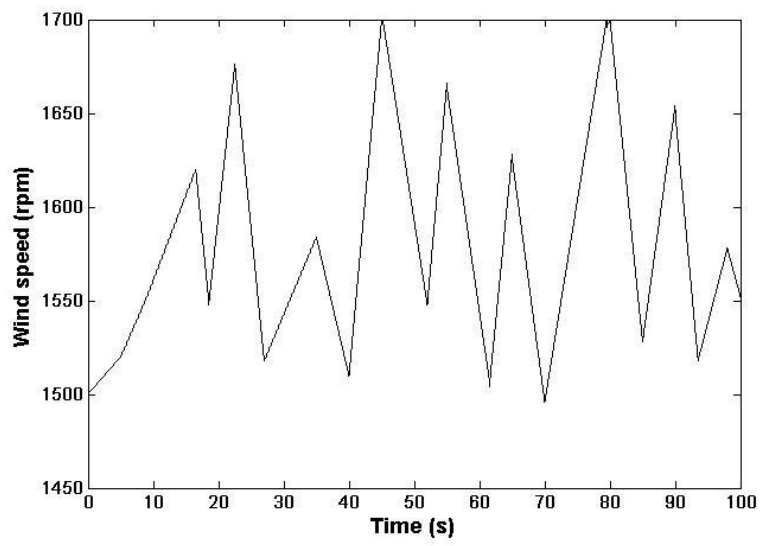

Fig. 4. Wind speed profile
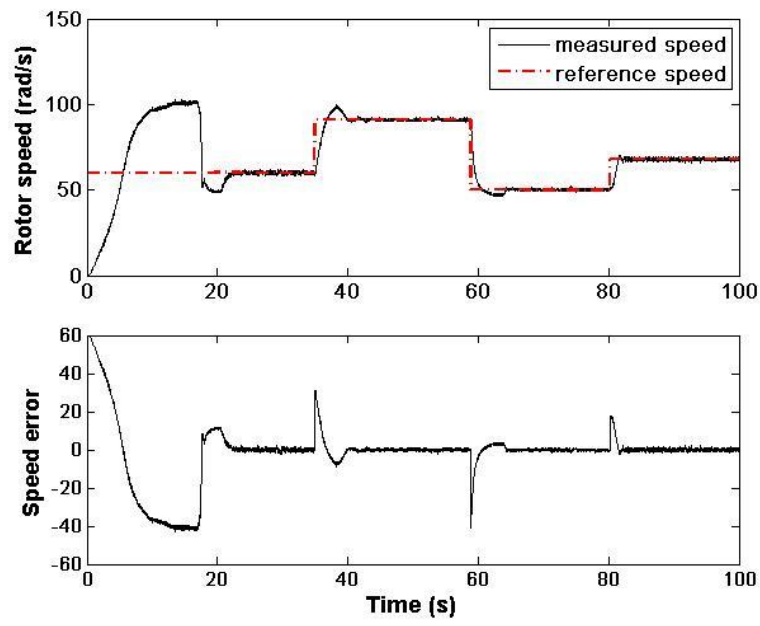

Fig. 5. Speed tracking and speed error for a variable speed reference

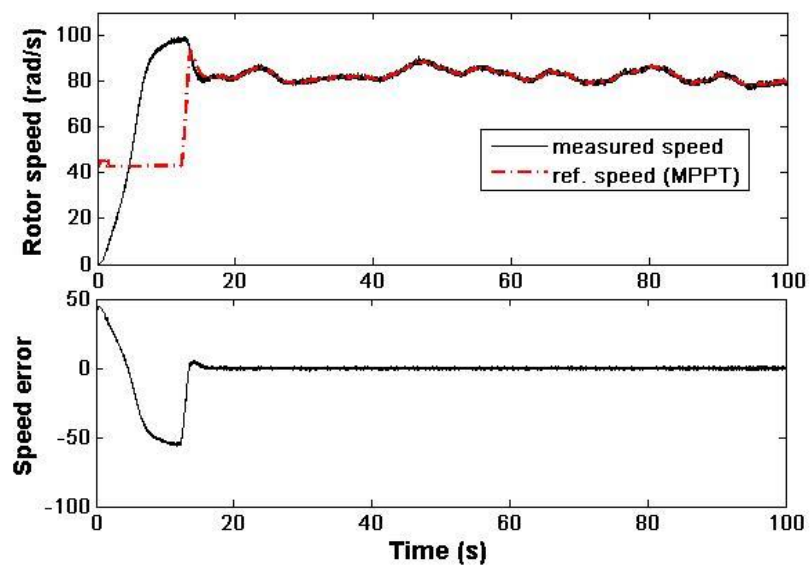

Fig. 6. Speed tracking and speed error for a speed reference generated from the MPPT controller 


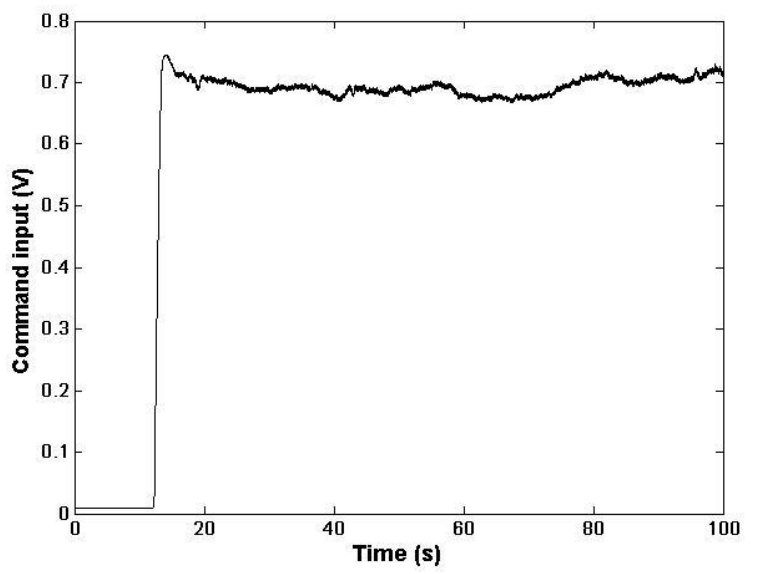

Fig. 6. Command input generated by the cascaded control system

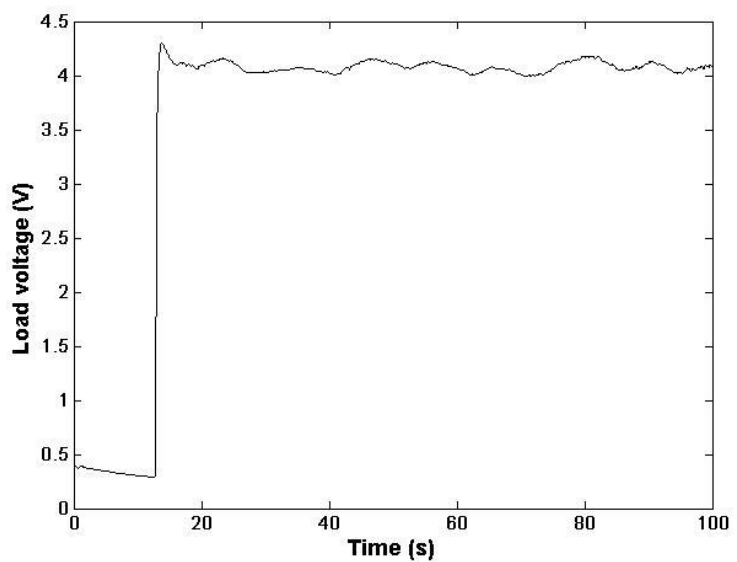

Fig. 7. Load voltage
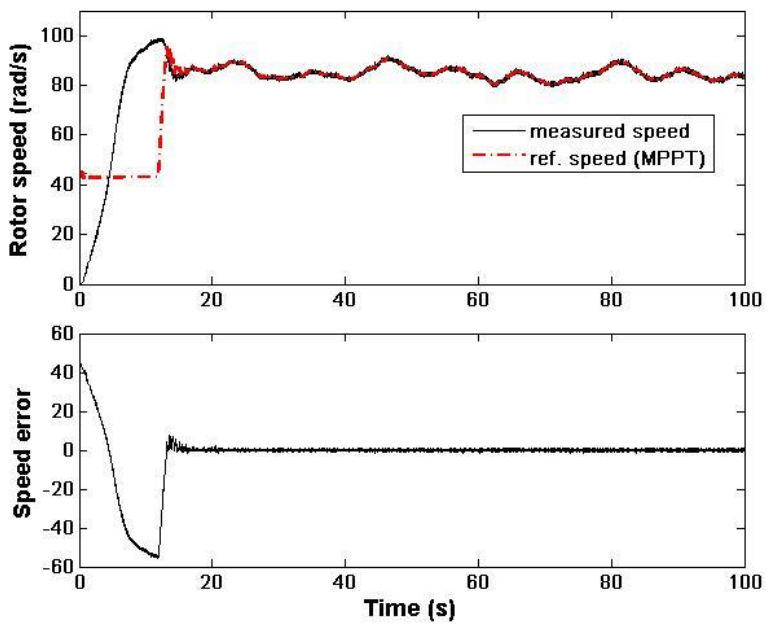

Fig. 8. Speed tracking and speed error for a speed reference generated from the MPPT controller under parameters' variations

\section{Conclusion}

A second-order sliding controller has been presented to track a speed profile in a wind turbine experiment system for operation at maximum power extraction. The unknown wind torque has been successfully rejected by the control system, which is robust against the variation of the parameters. Furthermore, the developed sliding mode controller provides good performance as a part a multivariable control system. The wind turbine experiment system can be used as an educational laboratory to develop and implement advanced control system.

\section{Appendix}

Wind turbine: $r=14 \mathrm{~cm}, \rho=1.14 \mathrm{~kg} / \mathrm{m}^{3}$.

DC generator: $R=3.705 \Omega, L=575 \mu \mathrm{H}, K_{b}=10.575 \mathrm{mV} / \mathrm{rpm}$, $K_{i}=100.95 \mathrm{mNm} / \mathrm{A}, J=165 \mathrm{~g} / \mathrm{cm}^{2}$

SMC (without MPPT): $k_{1}=10^{4}, k_{2}=10^{4}, K_{P}=2, K_{I}=4$

SMC (with MPPT): $k_{1}=10^{4}, k_{2}=10^{4}, K_{P}=0.2, K_{I}=5, \alpha=0.5$

Voltage controller: $k_{p}=5, k_{i}=0.1$.

\section{References}

[1] C. Evangelista, F. Valenciaga and P. Puleston, "Multivariable 2-sliding mode control for a wind energy system based on a double fed induction generator", International Journal of Hydrogen energy 37, 2012, pp. 10070-10075.

[2] H. Amimeur, D. Aouzellag, R. Abdessemed and K. Ghedamsi. "Sliding mode control of a dual-stator induction generator for wind energy conversion systems", Electrical Power and Energy Systems, 42, 2012, pp. 60-70.

[3] C. Evangelista, P. Puleston and F. Valenciaga, "Wind turbine efficiency optimization. Comparative study of controllers based on second order sliding modes", International Journal of Hydrogen energy, 35, 2010, pp. $5934-5939$

[4] B. Beltran, T. Ahmed-Ali and M. El Hachemi Benbouzid, "High Order Sliding Mode Variable-Speed Wind Energy Turbines", IEEE Transactions on Energy Conversion, vol. 56, no. 9, pp. 3314-3321, 2009.

[5] A. Merabet, J. Kerr, V. Rajasekaran and D. Wight, "Power Electronics Circuit for Speed Control of Experimental Wind Turbine," in $24^{\text {th }}$ International Conference of Microelectronics, December 17-20, 2012, Algiers, Algeria.

[6] J.A. Moreno and M. Osorio, "A Lyaponov approach to a second-order sliding mode controllers and observers", $47^{\text {th }}$ IEEE Conference on Decision and Control, Mexico, pp. 2856-2861.

[7] J. Rivera, L. Garcia, C. Mora, J.J. Raygoza and S. Ortega, "Super-Twisting Sliding mode in motion control systems" in "Sliding Mode Control", In-Tech, pp. 237-254.

[8] J.S. Thongam, P. Bouchard, H. Ezzaidi and M. Ouhrouche, "Wind speed sensorless maximum power point tracking control of variable speed wind energy conversion systems", in IEEE International Electric Machines and Drives Conference, Miami, USA, 2009, pp. 2195-2200.

[9] M. Zhou, G. Bao and Y. Gong, "Maximum power point tracking strategy for direct driven PMSG", in Proceedings of the Asia-Pacific Power and Energy Engineering Conference, Wuhan, China, 2011, pp. 1-4.

[10] A. Merabet, V. Rajasekaran, A. McMullin, H. Ibrahim, R. Beguenane and J. S. Thongam. "Nonlinear model predictive controller with state observer for speed sensorless induction generator-wind turbine systems", Journal of Systems and Control Engineering, 227(2), 2012, pp. 198-213.

[11] "Wind turbine experiment," Quick-Start Guide, Quanser Inc. Markham, Canada, 2010

[12] "Introduction to QUARC 2.0," Quanser Inc., Markham, Canada, 2010. 